\title{
Analysis of Diurnal, Interdiurnal and Interannual Variations during Northern Hemisphere Summers Using METEOSAT Infrared Channels
}

\author{
JeAN PHILIPPE DUVel \\ Laboratoire de Météorologie Dynamique du C.N.R.S., Ecole Polytechnique, Palaiseau, France
}

(Manuscript received 24 February 1987, in final form 16 June 1987)

\begin{abstract}
Using METEOSAT data in the ISCCP B2 format, we study the mean radiation fields and their fluctuations during Northern Hemisphere summer (June, July, August) of 1983, 1984 and 1985, for regions of $5^{\circ} \times 5^{\circ}$ located from $50^{\circ} \mathrm{N}$ to $50^{\circ} \mathrm{S}$ and from $60^{\circ} \mathrm{E}$ to $60^{\circ} \mathrm{W}$. The study is performed for the IR atmospheric window channel $(10.5-12.5 \mu \mathrm{m})$ and the water vapor band $(5.7-7.1 \mu \mathrm{m})$. The year-to-year differences of the mean fields delineate large regions of positive and negative anomalies with principally a zonal distribution. This suggests that interannual perturbations in the large-scale meridional circulation have a strong influence on the radiation field, principally by way of convective activity.

To study diurnal variations, we separate coherent diurnal variance obtained by compositing over the 3 months, and the total intradiurnal variance obtained by integration of the power spectra over periods lower than 1 day. In the IR window, the coherent diurnal variance, expressed as a percentage of the total intradiurnal variance, is stronger over subsidence areas, reaching values greater than $98 \%$ over desert regions due to surface temperature and values near $70 \%$ over ocean regions due to diurnal variations of stratiform cloudiness. Over ITCZ or midlatitude regions, this percentage is lower. In the WV band, the latitudinal distribution presents maximum values of this percentage between the equator and $10^{\circ} \mathrm{N}(>35 \%)$ with a progressive decrease up to $30^{\circ}$ of latitude $(<5 \%)$ in both hemispheres. The coherent diurnal variation is larger (up to $50 \%$ ) over central and eastern Africa and related to convective activity over highlands.

Spectral analysis of interdiurnal fluctuations reveals a progressive shift of the dominant time scales from short time scales (1-2.5 day band) over convective zones to periods longer than 9.2 days over subsidence areas. Regional aspects are revealed by mapping the spectral variance in selected frequency bands as a percentage of the total interdiurnal variance. Over subsidence areas and many other regions where the IR signal depends strongly on surface temperature and lower atmospheric levels inaccessible to the WV channel, the strong coherence between the two channels suggests that the same time scales dominate over the entire vertical extent from low to middle troposphere.
\end{abstract}

\section{Introduction}

Infrared radiation in the atmospheric window (IR) is highly sensitive to surface temperature and to cloudiness, especially for high convective clouds. Previous study (Nitta et al., 1984) has shown that fluctuations of the outgoing longwave radiation (OLR) (computed by NOAA principally from $11 \mu \mathrm{m}$ window data) are strongly coupled with tropospheric wind disturbances at $850 \mathrm{mb}$ by way of convection. Other authors (Weickmann, 1983; Lau and Chan, 1985; Murakami et al., 1986) using satellite-derived OLR, have studied characteristic features of low-frequency tropospheric oscillation. The International Satellite Cloud Climatology Project (ISCCP) (Schiffer and Rossow, 1983) giving $3 \mathrm{~h}$ data since summer 1983 offers the opportunity to study fluctuations of the OLR at diurnal, interdiurnal and interannual time scales.

Corresponding author address: Dr. Jean Phillippe Duvel, Labortoire de Meteorologie Dynamique du C. N. R. S., Ecole Polytechnique, 91128 Palaiseau, France.
Spectral analysis of the fluctuations in the atmospheric window yields the characteristic time scales of intraseasonal tropospheric disturbances. This is very important for validating GCMs since these should predict the fluctuations related to physical atmospheric processes as well as mean values. Another important feature revealed by the infrared measurements of geosynchronous satellites such as METEOSAT is the diurnal cycle. It is especially strong over desert areas due to the surface temperature, and over convective areas due to diurnal fluctuation of high cloud cover but it is also detectable over oceanic subsidence areas due to stratiform cloud (Minnis and Harrison, 1984; Duvel and Kandel, 1985).

Complete diurnal sampling made by geosynchronous satellites is important not only for the study of diurnal variation but also for the study of interannual and intraseasonal fluctuations. For many such studies, the manageable ISCCP geostationary satellite datasets are far preferable to longer series of sun-synchronous polar orbiter data. In fact, over some regions, seasonal means based on sun-synchronous satellite data (two measurements per day) depend strongly on the times 
of day at which the observations are made. Interannual comparisons of seasonal means based on measurements at different hours of day-for example, summer 1980 with NOAA-6 (0730-1930 LST) and summer 1982 with NOAA-7 (0230-1430 LST)-will then give an erroneous result if the diurnal cycle has not been correctly modeled. Note that even in the case of comparison between seasonal means from measures at the same hours, the amplitude of the interannual change may also be shifted because some features presenting interannual (or seasonal) variations are also highly dependent on time of day (e.g., convective cloud, oceanic stratocumulus, ground temperature). For the same reasons, spectral analysis is also perturbed by the diurnal sampling because some features present both characteristic interdiurnal time 'scales and diurnal dependence.

Knowledge of diurnal variations is then important to correct the bias due to the measurement of the earth's radiation budget by sun-synchronous satellites and also to reveal the response of the earth-atmosphere system to the solar forcing.

In this study, the water vapor channel (WV) of METEOSAT $(6-7 \mu \mathrm{m})$ is also used. This channel is affected by the water vapor content in the midtroposphere, the temperature at which the vapor occurs and by high cloud. This channel allows continuous monitoring of upper tropospheric features such as the jet streams (Martin and Salomonson, 1970; Ramond et al., 1981). The signal is also partly related to large-scale vertical motion, subsidence being associated with dry regions and convection with high water vapor content. However, as shown by Stewart and Fuelberg (1986), there is not a direct relationship since warm (dry) areas are in some cases associated both with subsidence and horizontal water vapor flux divergence.

This study is based on the analysis of a 3-year dataset during the Northern Hemisphere summer (June, July, August) corresponding to the season of important convective activity related to the West African monsoon. In section 3 we discuss the seasonal mean fields and, in section 4, their interannual variation over the 3 years for each of the two channels. We also examine the interdiurnal standard deviation fields, as a first step in the study of fluctuations. In section 5 we study diurnal variation and perform spectral analyses of the time evolution of the signal in the atmospheric window and in the water vapor channels so as to examine the spatial distribution of the spectral variance in different spectral bands. The results of these analyses are discussed in section 6 .

\section{Description of the dataset and method of analysis}

The data for the present study consist of 3-h sampling of IR (10.5-12.5 $\mu \mathrm{m})$ and WV (6-7 $\mu \mathrm{m})$ METEOSAT ISCCP B2 data for summers (June, July, August) 1983, 1984 and 1985. In order to have a better comparison among the 3 years we applied the METEOSAT Me- teorological Information Extraction Center (MIECESOC) (Jones and Morgan, 1981) adjustment which gives an estimate of the radiance in the two channels. This calibration converts raw counts $(0-255)$ into radiances, expressed in $\mathrm{W} \mathrm{m}^{-2} \mathrm{sr}^{-1}$, as measured by the radiometers taking into account their spectral responses. The aim of this study is not to do an exact measurement of the outgoing longwave radiation but to analyze in detail the geographical distribution of fluctuation at different time scales. For this type of study, an absolute calibration is not needed because it is primarily relative values which are interesting. In what follows, a large part of the results will then be expressed as a percentage. The area of investigation is the large area between $-50^{\circ}$ and $50^{\circ} \mathrm{N}$ and $-60^{\circ}$ and $60^{\circ} \mathrm{E}$. This area is divided into 480 regions of $5^{\circ} \times 5^{\circ}$. Since ISCCP B2 data are a sampling of the initial image (1/36 pixel), each region contains from 55 sampled pixels at the corners to 375 sampled pixels at the subsatellite point. The study is performed on the regional mean value of the IR or WV channel for each of the 736 available 3-h observation times between 31 May (2330 UTC) and 31 August (2330) with eight measures per day. The missing data are linearly interpolated (2.3\% in $1983,2.7 \%$ in $1984,3.1 \%$ in 1985$)$. In the 1985 dataset there are 18 consecutive missing observations, i.e., 2.25 days. To fill this gap we make an interpolation between the same hours of the day in order to keep diurnal variation. The midnight observation of the WV channel is systematically interpolated because of the bad quality of the measurements due to sunlight getting into the optics.

Spectral analysis is based on the fast Fourier transform (FFT) of the dataset $U_{x}(t)$ where $x$ is the number of the region $(1 \leqslant x \leqslant 480)$ and $t$ is time $(1 \leqslant t \leqslant 736)$ with a 3-h step. For the study of intradiurnal fluctuations, we first remove the mean value of the time series of each region and we multiply the first and last 72 time steps of the record by a segment of a cosine curve. This tapering operation proposed by Julian (1971) minimizes end effects. For the study of interdiurnal variations, we perform a linear detrending with a leastsquare regression method. The final result is a power spectrum $P_{x}(k)$ where $k$ is the frequency corresponding to periods between 0.25 and 92 days. The values $P_{x}(k)$ are drawn after smoothing with weights $(1 / 4,1 / 2$, $1 / 4)$. In what follows, the variance in the spectral band $\left(k_{1}, k_{2}\right)$ for each season is computed using

$$
V_{x}\left(k_{1}, k_{2}\right)=\sum_{k=k_{1}}^{k_{2}} P_{x}^{2}(k) / 2 .
$$

\section{Mean field and standard deviation of the IR and WV signals}

a. Mean values

Figure 1 gives the mean summer fields averaged over the 3 years. In each region the mean IR signal is affected 

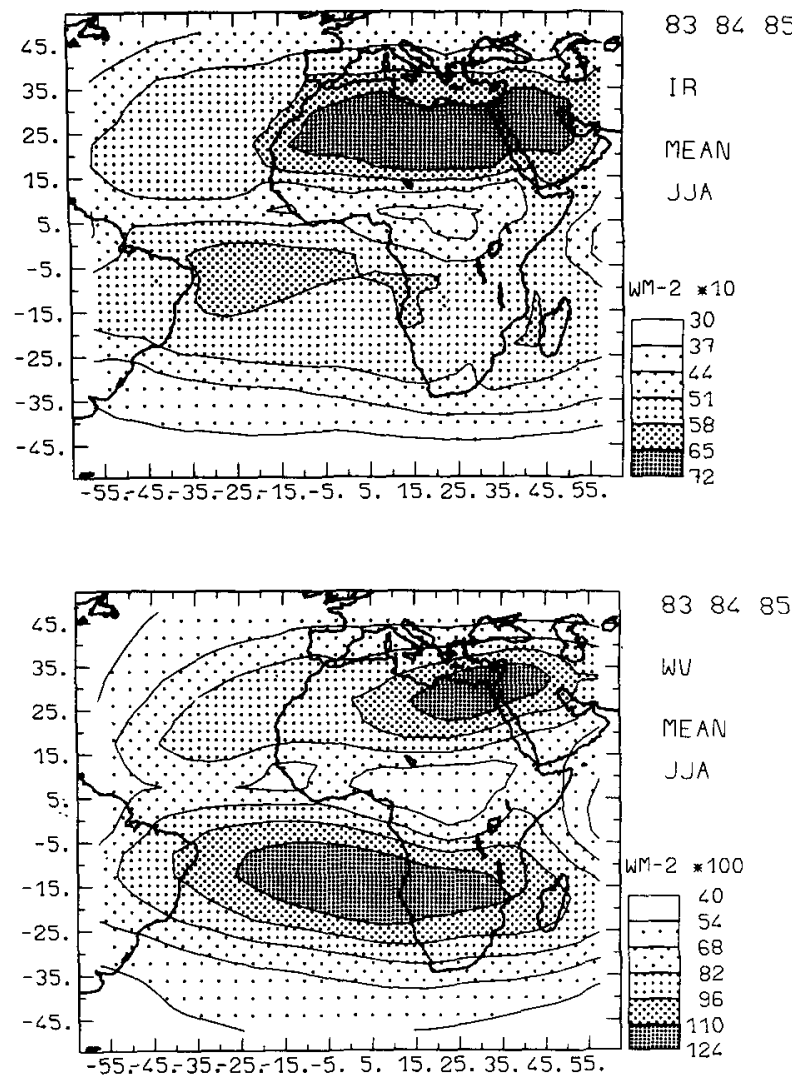

FIG. 1. Mean fields over the three summers for the IR window and the water vapor channel. Radiances, computed using the MIEC adjustment, are expressed in $\mathrm{W} \mathrm{m}^{-2} \mathrm{sr}^{-1}$ and are scaled by 10 for the IR window and by 100 for the WV channel.

by the surface temperature, the horizontal and vertical extension of cloudiness and the atmospheric extinction mainly due to water vapor. For the three summers, low IR values are associated with the intertropical convergence zone (ITCZ) giving high-level clouds roughly between $5^{\circ}$ and $15^{\circ} \mathrm{N}$ for regions west of $10^{\circ} \mathrm{E}$ and extending to $5^{\circ} \mathrm{S}$ for regions of central Africa. The break in the ITCZ around $45^{\circ} \mathrm{E}$ is explained by the concentrated southerly flow (East African jet) across the equator. This is due to the deviation and channeling near the East African coast of the southeast trades of the western Indian Ocean. The result is the northeastward flow into the southwest monsoon over the Arabian Sea (Paegle and Geisler, 1986). Further east, there is low IR radiance related to the convective activity generated by the Indian monsoon. During this season, the Sahara appears to have the largest value of mean radiance in the atmospheric window. This remains true considering total OLR over the whole globe as was shown using Nimbus-7 ERB narrow-field-of-view data (Hartmann et al., 1986). This is due to the warm surface of the Sahara Desert emitting through a relatively dry and cloud-free atmosphere. The mean value of the IR signal is also strong over the oceanic subsidence areas where no high clouds are present. Over the midlatitude areas, the mean IR is lower especially in the Southern Hemisphere where the winter perturbations are strong.

Some regional features also appear, such as the smaller mean IR radiance over the eastern part of the South Atlantic, due to persistent low-level stratiform cloud. There is also a relatively higher mean IR radiance over the land part of the ITCZ around $5^{\circ} \mathrm{W}$ which is undoubtedly due to a reduced cloud amount in this part of the convergence zone. The west coast of Madagascar and adjacent ocean, located in this season on the leeward side of the main mountain range, has an enhanced IR radiance corresponding to a low amount of cloud and associated with low rainfall (Nieuwolt, 1977). Over the Amazon Basin, there is low IR radiance related to high cloudiness observed at a large zenith angle. The latitudinal distribution of the mean radiance has two maxima at $25^{\circ} \mathrm{N}$ and $10^{\circ} \mathrm{S}$ and a minimum at $10^{\circ} \mathrm{N}$ due to the presence of the ITCZ.

In the WV channel, the mean value is mainly influenced by the water vapor content of the midtroposphere and the amount of high-level cloud. The distribution of the mean WV signal (Fig. 1) reveals the location of the ITCZ associated with low radiance due to high-level cloud and high water vapor content with again a larger signal around $5^{\circ} \mathrm{W}$ and a break around $45^{\circ} \mathrm{E}$. These maps show, in addition, the zonal distribution of the dry air located over large-scale subsidence areas. The two driest regions are located over the South Atlantic and the eastern part of the Mediterranean $\mathrm{Ba}$ sin. Over Atlantic regions north of the ITCZ, the WV signal is lower.

In the Southern Hemisphere, the "dry" region corresponds to large-scale atmospheric subsidence which appears to be most intense over the oceanic upwelling region of the west coast of southern Africa at $15^{\circ} \mathrm{S}$. Over the South Atlantic, the dry areas are located equatorward of the St. Helena high pressure. The southern (i.e., poleward) part of this driest region is affected by the subtropical westerly jet which gives a low WV signal related to the advection of water vapor in the midtropospheric layers and to the development of cirrus. This southern limit is also affected by highlevel cloudiness induced by midlatitude perturbations. Of course, the poleward reduction in the WV signal is, in part, due to the poleward temperature decrease in the middle troposphere, and limb darkening also has some effect here (as it does on the extreme east and west of the images). However (Fig. 2), the high standard deviation at the poleward limit of the zone of high WV signal suggests that the poleward (especially western) side of the South Atlantic subsidence is indeed wetter on the average despite subsidence motions which may occur at lower levels and which are detected when there is no water vapor advected by the jet. This is also true in the Northern Hemisphere where there is water vapor advected over the northwestern part of the Sahara and the adjacent Atlantic Ocean. The latitudinal distribu- 

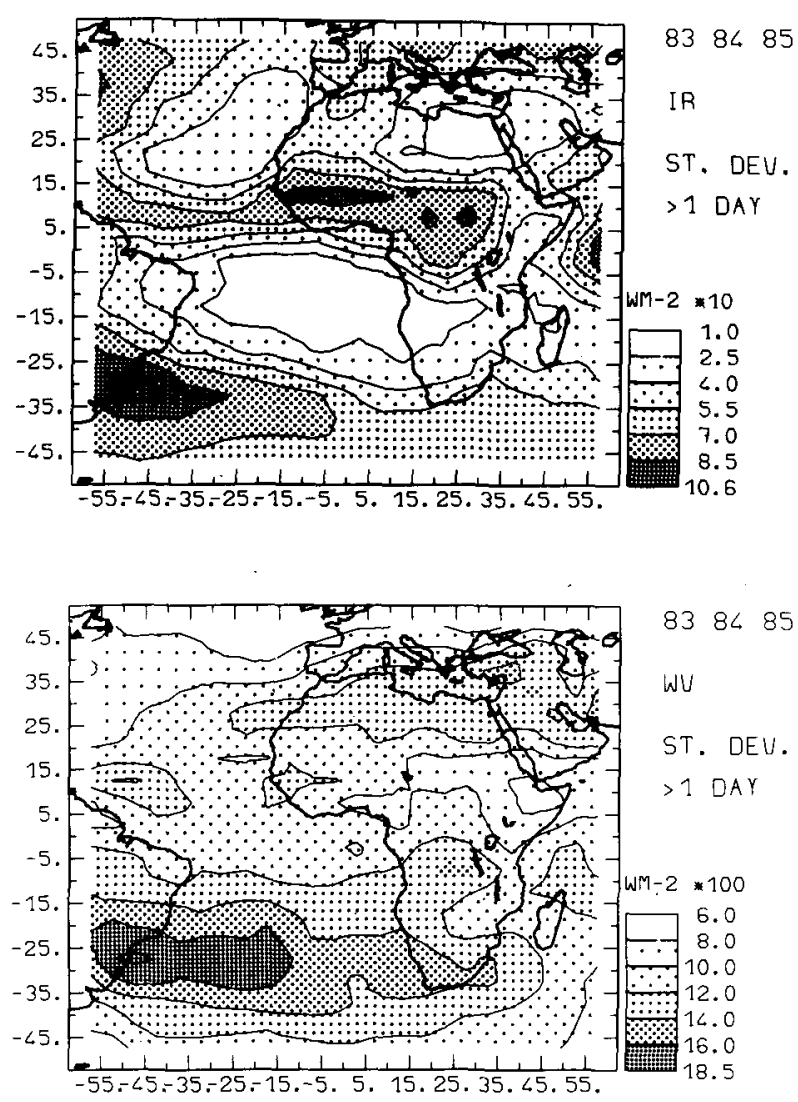

FIG. 2. Mean for the three summers of the interdiurnal standard deviation of the detrended signals for the IR window and the WV channel.

tion of the mean WV signal has two maxima at $15^{\circ} \mathrm{S}$ and $25^{\circ} \mathrm{N}$ corresponding to the driest regions.

\section{b. Standard deviation}

In the IR channel, radiance fluctuations are mainly due to fluctuations in high-level cloud cover and surface temperature. The surface temperature is strongly affected by diurnal variation which represents a large part of the fluctuations over desert area as discussed in section 5a. However, interdiurnal surface temperature fluctuations are relatively unimportant compared to fluctuations of high-level cloud cover in accounting for the interdiurnal fluctuations of the IR window radiances. The regional distribution of the standard deviation of the detrended interdiurnal (see section 2) fluctuations (Fig. 2) shows a general pattern out of phase with the fields of mean value. Regions of high mean value have a low standard deviation of the signal because they correspond to stable areas, whereas regions with low mean value correspond to areas of instabilities associated with high level cloud perturbations and large interdiurnal standard deviation. For regions having mean values of the same order, those which have higher standard deviation correspond to regions affected by higher but less persistent cloud cover. This is the case over western Africa around $15^{\circ} \mathrm{N}$ which is affected by high convective disturbances related to thunderstorms or squall lines near the ITCZ. Regions further south are mostly affected by persistent midlevel clouds. The southern Brazilian coast and adjacent ocean also appear to be more affected by high convective disturbances than regions located further east. This type of feature also exists over the North Atlantic Ocean around $55^{\circ} \mathrm{W}$, and over the equatorial Indian Ocean. Over the northwestern part of the Sahara, there is also an enhanced standard deviation which is principally due to cirrus clouds presenting a strong contrast with the surface. This region is located between the two subtropical high pressure areas of the Azores and the eastern Mediterranean Sea and represents a band of low pressure and water vapor advection.

In the WV channel, fluctuations are due, in part, to high cloud but they are also strongly affected by the water vapor content and the temperature of the midtroposphere. The diurnal variation is mainly due to high cloud (see section $5 b$ ). The weakness of the interdiurnal standard deviation (Fig. 2) over the ITCZ shows that high cloud activity gives a small deviation of the WV signal in these regions where the water vapor content of the midtroposphere remains high during the entire period studied. The regions with maximum interdiurnal fluctuation are located east of the Brazilian coast and are associated with midlatitude perturbations and the subtropical jet. There are also stronger fluctuations over the northern part of the subsidence area of the East Mediterranean basin and, more generally, on the poleward part of the subsidence area. Over these regions, contrast between dry and hot subtropical air masses and wet and cold midlatitude ones gives strong standard deviations. This shows that the interdiurnal standard deviation in the WV channel is primarily due to the fluctuations of water vapor amount (and temperature) in the midtroposphere induced by different air masses rather than local fluctuations of high cloudiness appearing generally in regions of large amount of water vapor.

\section{Interannual changes}

During the 3 yr studied there was large interannual variability of the atmospheric circulation. In 1983, the El Niño event over the Pacific Ocean involved a large departure from normal atmospheric circulation over this region. This seems to be related to stronger than normal trade winds over the South Atlantic (Horel et al., 1986). In 1984, trade winds relaxed and this was associated with a positive SST anomaly over the South Atlantic (Philander, 1986; Weisberg and Colin, 1986; Katz et al., 1986). These two summers both present extremely low rainfall over the Sahelian zone compared to the mean rainfall for the 1940-85 period (Lamb et al., 1986). This drought over the Sahel is associated in 1984 with exceptionally heavy rainfall over the coastal zone from Liberia through Cameroon (southern West 
Africa, SWA) during the summer season. By contrast, in 1985 , conditions were closer to "normal" although the amount of rain over subsaharan West Africa was well below the 1940-85 mean. Analysis of interannual changes observed by METEOSAT in the 1983-85 period is possible, even though the ESOC MIEC calibration is relatively crude. We consider year-to-year differences of the mean fields in the two channels. These differences (Fig. 3) reveal principally large anomalies (appearing on the two channels) over SWA and northeastern Brazil (NEB).

Over the south coast of SWA, there is a weaker signal in 1984 associated with more convective activity related to a southerly position of the ITCZ. North and south of the anomaly, there is a larger mean IR radiance in 1984 over the Sahelian zone and over the eastern part of the South Atlantic. The second event is certainly due to a lower amount of stratiform cloud in 1984 associated with the higher SST and to the weak eastern branch of the trade winds as was shown by Kraus and Leslie (1982). Over the Sahelian zone, this larger IR radiance in 1984 is due also to the more southerly position of the ITCZ related to a smaller cloud cover in the north. The anomaly has a large extent from the Atlantic Ocean to the Red Sea and up to $25^{\circ} \mathrm{N}$. This large anomaly may then be due to anomalies in surface temperature (by way of the sensible heat flux) and, since it also appears in the WV signal, to anomalies in the water vapor content or high level cloud. The comparison between 1983 and 1985 gives a larger IR signal over all SWA showing the lack of high cloud related to the low amount of rain during summer 1983.

Compared with 1983, 1985 (and 1984 with less amplitude) presents a larger cloud cover over NEB corresponding to a southward displacement of the subtropical westerly jet in 1983 . This jet is detected by METEOSAT through water vapor content or cirrus located over a band oriented northwest-southeast. This anomaly is associated in 1983 with a lower mean IR radiance north and south of NEB. This result suggests that the Atlantic part of the ITCZ north of $5^{\circ} \mathrm{N}$ gives more cloud cover for summer 1983. Results in the WV channel show a stronger signal in 1983 over a large region roughly located west of $20^{\circ} \mathrm{E}$ and between $10^{\circ} \mathrm{N}$ and $20^{\circ} \mathrm{S}$. This suggests less high-level clouds and water vapor content, and may be related to stronger subsidence especially over NEB. Another feature is the smaller WV signal over the eastern part of the Mediterranean basin in 1983 compared to 1984 and 1985 suggesting wetter air possibly related to weaker subsidence. The latitudinal distribution is affected by these events giving a weaker value in 1983 at $25^{\circ} \mathrm{N}$ and, at $15^{\circ} \mathrm{S}$, a progressive decrease of the signal between 1983 and 1985.

The overall spatial distribution of differences between 1985 and 1984 presents a zonal shape suggesting higher cloud activity in 1985 over the Sahel and the South Atlantic and, more generally, a latitudinal shift of the main convective zones. Comparison between 1983 and the two other years presents in addition a marked dependence on longitude around $15^{\circ} \mathrm{W}$ with, in 1983, less cloud activity over NEB and SWA and more cloud activity over the Atlantic part of the ITCZ and over the eastern part of the South Atlantic.

Interannual variations of the interdiurnal standard deviation (Fig. 4) of the IR signal reveal roughly the same structures as the mean field with an out-of-phase relation for regions of high cloud cover. In 1985, the Brazilian subtropical jet over NEB is associated with a high standard deviation due to high cloud. South of the jet there is a region of more stable atmospheric conditions giving lower fluctuations and higher mean value. On the contrary, the IR standard deviation is weaker in 1983 over NEB and the equatorial Atlantic, in relation to the more stable atmosphere also detected by way of the stronger WV mean. For the stratiform cloud coverage over the eastern part of the South Atlantic, the increased cloudiness in 1983 is related to a lower value of the interdiurnal fluctuation corresponding to a more persistent cloud cover.

In the WV channel, year-to-year differences (Fig. 4) do not give a simple shape directly associated to anomalies in the mean field. In fact, some features associated with high-level cloud present low standard deviations related to persistent water vapor content in the midtroposphere. The lower value of the mean WV signal over the south coast of SWA in 1984 is not related to an increased standard deviation in contrast to the case for the IR.

\section{Spectral analysis of the fluctuations}

In section $3 \mathrm{~b}$ we saw how the standard deviation of the IR signal is related to atmospheric conditions through cloud development, with high interdiurnal variation over regions of high convective activity or regions of cirrus development and low variation over subsidence areas. More precisely, as shown by Nitta (1984) using FGGE data of tropical wind at $850 \mathrm{mb}$, the fluctuations of OLR, related to convective activity are strongly coupled with large-scale tropospheric disturbances. In the WV channel, the magnitude of the standard deviation is also influenced by high cloud but appears to be mostly related to the water vapor content of the midtroposphere. This is illustrated by the strong standard deviation over the poleward limit of subsidence areas compared to the ITCZ.

In this section we determine the geographical distribution of the dominant time scale of the fluctuations which are associated with characteristic atmospheric states. For this we study separately diurnal variation, associated with the regional response to the solar forcing, and interdiurnal fluctuations which are more related to large-scale tropospheric disturbances. From this point of view, a separation between these two domains gives much more information since there may be com- 

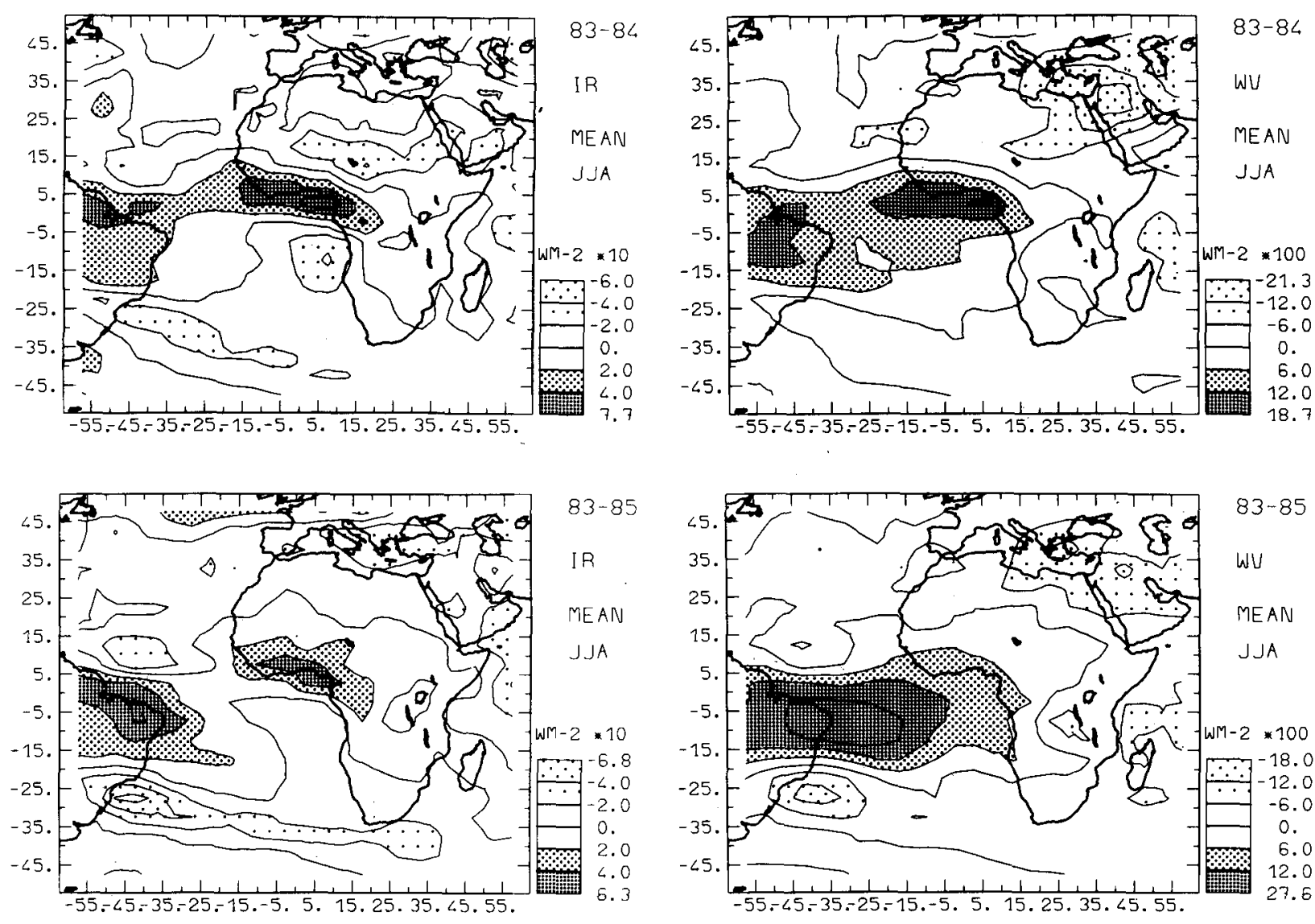

$83-85$

WU

MEAN

$J\lrcorner A$
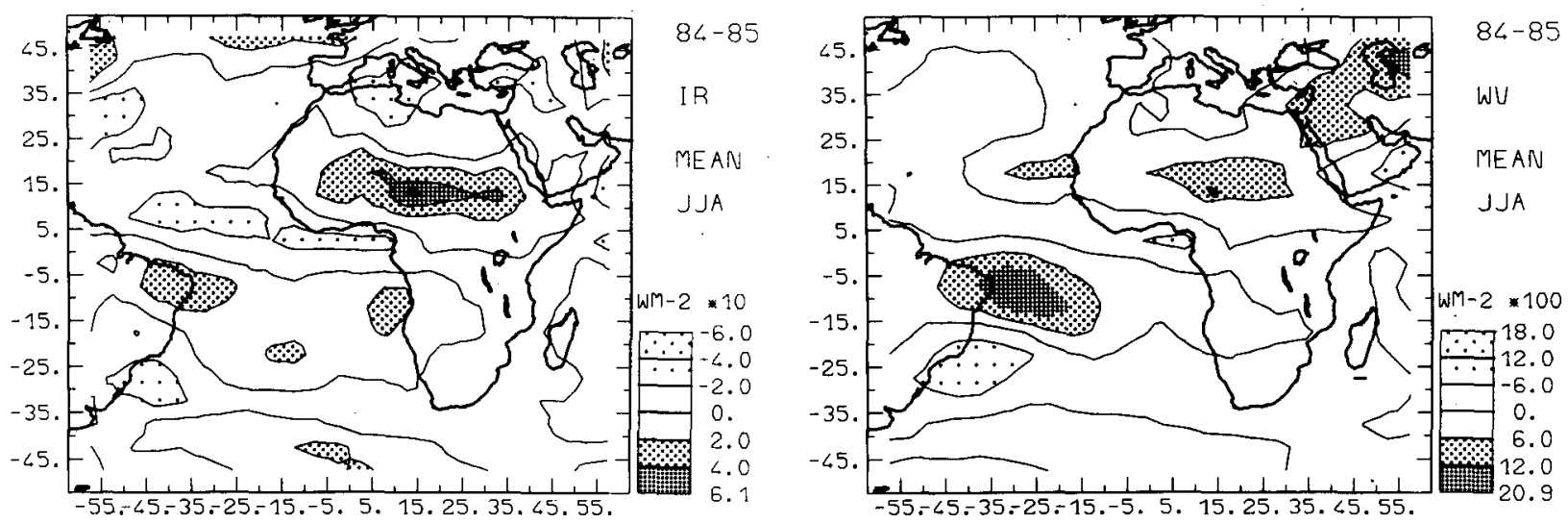

FIG. 3. Year-to-year differences of the mean fields for the IR window and the WV channel.

pensation between them. For example, the smaller interdiurnal variance in 1984 (compared to 1985) over the Sahelian regions is related to a larger intradiurnal variance. This is due, firstly, to an increase of interdiurnal variations in 1985 due to the presence of cloudiness induced by large-scale tropospheric disturbances. Secondly, the presence of cloud perturbs the IR signal and the diurnal response of the surface temperature itself by reduced insolation and by wetting the soil (when it rains). The study of differences in the total variance between 1984 and 1985 (not shown) gives, then, no large anomaly in this region. By contrast, the two spectral bands considered separately give large anomalies.

\section{a. Diurnal variation in the atmospheric window}

In the atmospheric window the variance for periods shorter than or equal to 1 day (Fig. 5) is very strong over desert areas due to diurnal variation of surface 

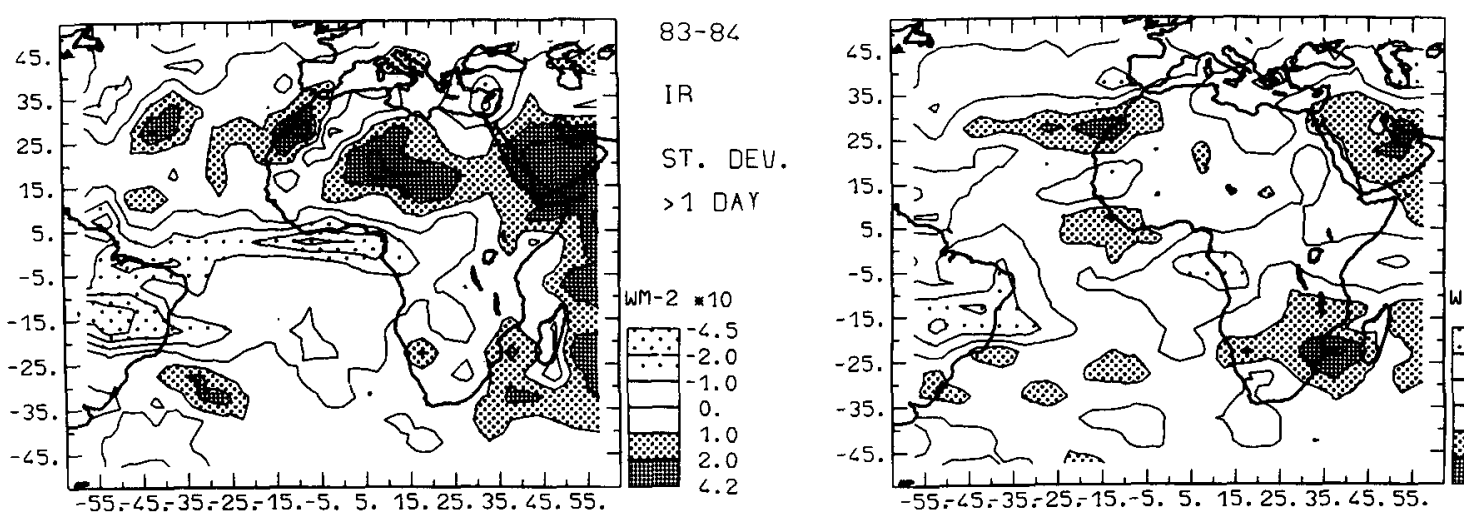

83-84

WU

ST. DEV.

$>1$ DAY
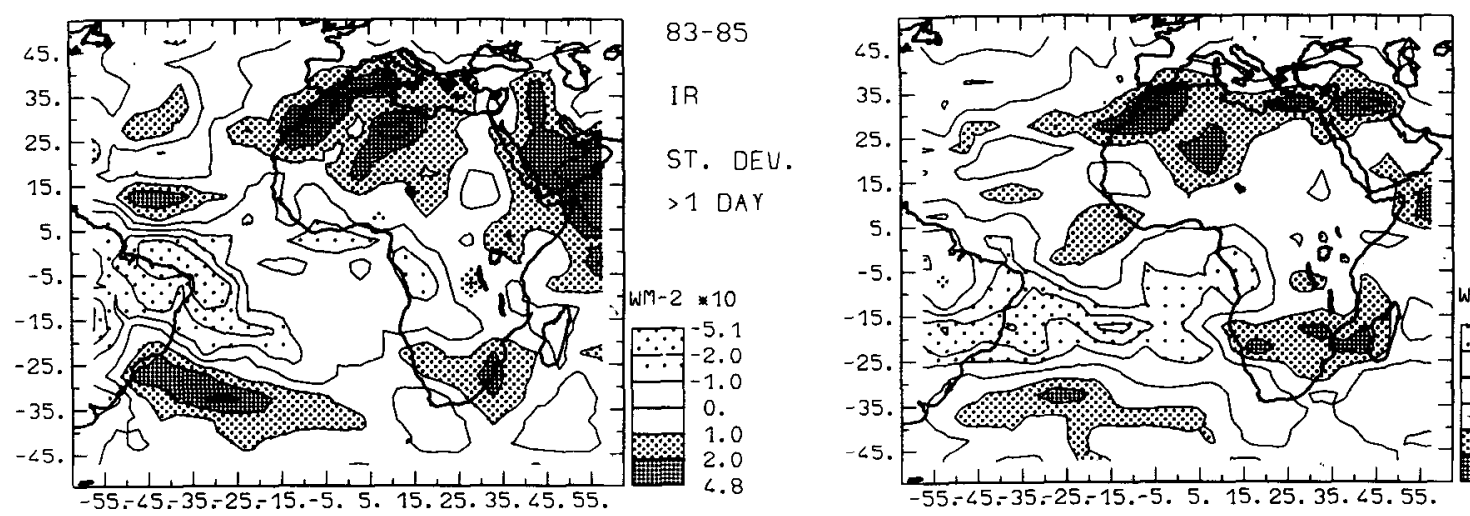

$83-85$

WU

ST. DEV.

$>1$ DAY

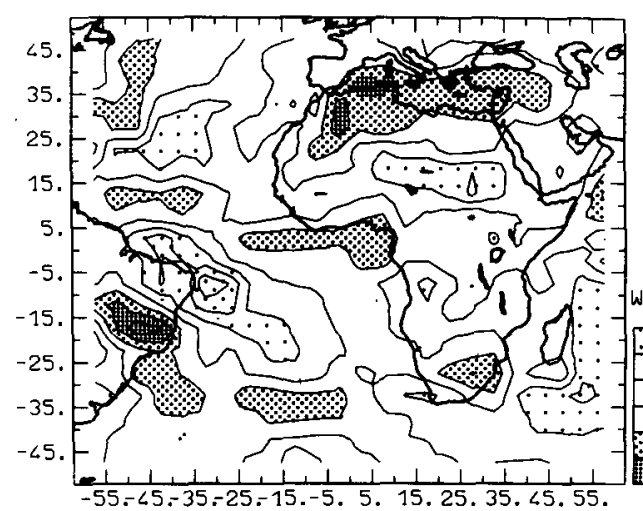

$84-85$

IR

ST. DEV.

$>1$ DAY

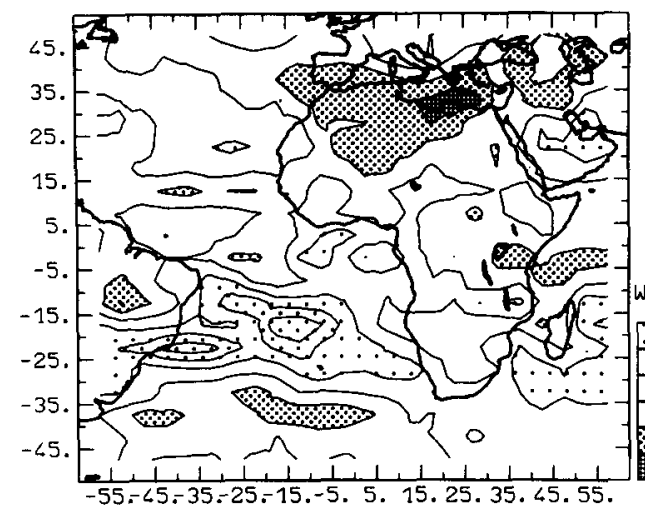

$84-85$

WU

ST. DEV.

$>1$ DAY

Fig. 4. Year-to-year differences of the interdiurnal standard deviation fields.

temperature. For these regions we may see, comparing with Fig. 2, that these intradiurnal variation are nearly two to four times stronger than interdiurnal fluctuations. On the contrary, for the land part of the ITCZ, the intradiurnal variance is nearly two times weaker than the interdiurnal variance. Over the oceanic part of the ITCZ, intradiurnal fluctuations are very weak. In order to see the proportion of coherent diurnal variation in the total intradiurnal variation, we compute the variance of the composite diurnal variation given by

$$
D_{x}(h)=1 / J \sum_{i=1}^{J} U_{x}\left(h_{i}\right)
$$

where $J$ is the total number of days for each summer (92) and $1 \leqslant h \leqslant 8$ with a step of 3 h. In Fig. 6 we show the spatial distribution of this coherent diurnal 

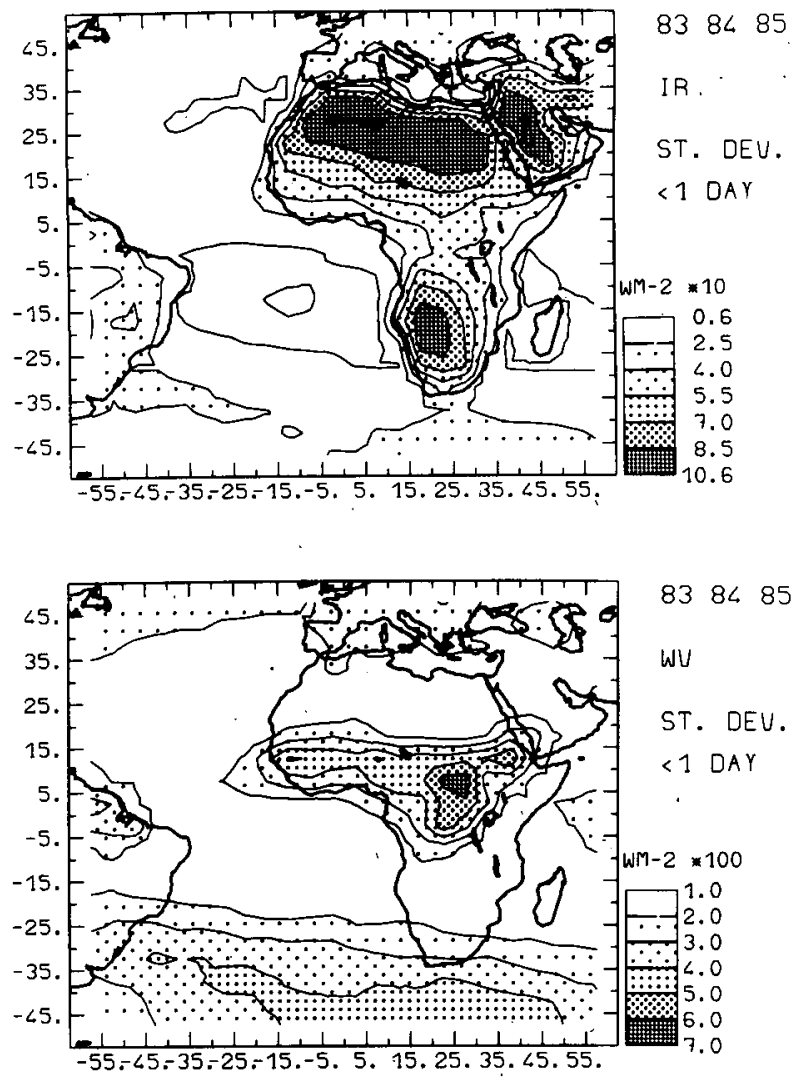

FIG. 5. Mean intradiurnal standard deviation over the three summers for the two channels.

variance expressed as a percentage of the total intradiurnal variance. With the assumption that this coherent diurnal variation is directly related to the summer mean regional response to the solar forcing, we may see that for most of the subsidence area this response represents a large part of total intradiurnal variations. This is evident over desert areas for which this response is due to surface temperature, but the percentage is also strong, reaching values near $70 \%$, over the South Atlantic subsidence area and $60 \%$ over the North Atlantic around $25^{\circ} \mathrm{N}$. This is due to the coherent diurnal variation of stratiform cloud (Short and Wallace, 1980; Minnis and Harrison, 1984; Duvel and Kandel, 1985; Hartmann and Recker, 1986) which appears to be strongest over the regions centered at $10^{\circ} \mathrm{S}$, $10^{\circ} \mathrm{E}$. In 1984 , perhaps in relation to the SST anomalies over the southern Atlantic, the percentage of coherent diurnal variation of stratiform cloud appears to be lower, especially over the equator between $10^{\circ} \mathrm{E}$ and $20^{\circ} \mathrm{W}(-20 \%)$ but also over the upwelling region of the western South African coast $(-10 \%)$.

In the ITCZ this percentage is lower showing the large influence ( $>50 \%$ in some regions) of incoherent intradiurnal variations due to the development of cloud at a random hour of the day or to the passage of west- ward moving perturbations across the region generating short time-scale fluctuations (squall lines). The percentage of coherent diurnal variation is also reduced over the lower terrain of the southern Sudan and northern Congo showing the strong influence of topography on the coherent diurnal variation of high convective clouds. The coherent diurnal variation of convection in these regions may be reduced by the outof-phase vertical motion generated by the surrounding highlands. The coherent diurnal variation is also very low $(<10 \%)$ over the Atlantic portion of the ITCZ and over the midlatitudes.

The latitudinal distribution of this quantity (Fig. 7) shows clearly that the coherent diurnal variation has maxima located over subsidehce areas. Comparison between 1983 and the other two years shows, in addition, a weaker percentage over the northern part and greater over the southern part in 1983 mainly due to differences in the coherent diurnal variation of surface temperature over NEB and the Sahara.

\section{b. Diurnal variation in the water vapor channel}

In the WV channel (Fig. 5), intradiurnal variations are stronger over midlatitudes and over the Amazon basin, SWA and central Africa corresponding to the land part of the ITCZ. The magnitude of these varia-
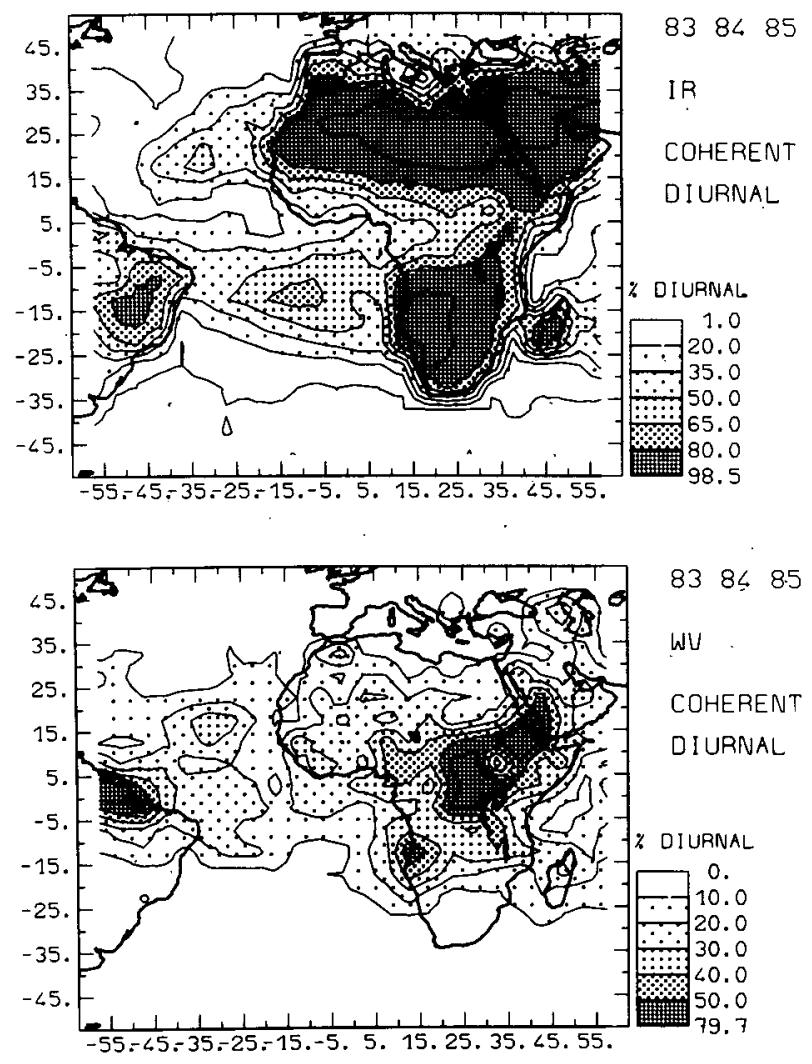

FIG. 6. Coherent diurnal variance as a percentage of the total intradiurnal variance for the two channels. 

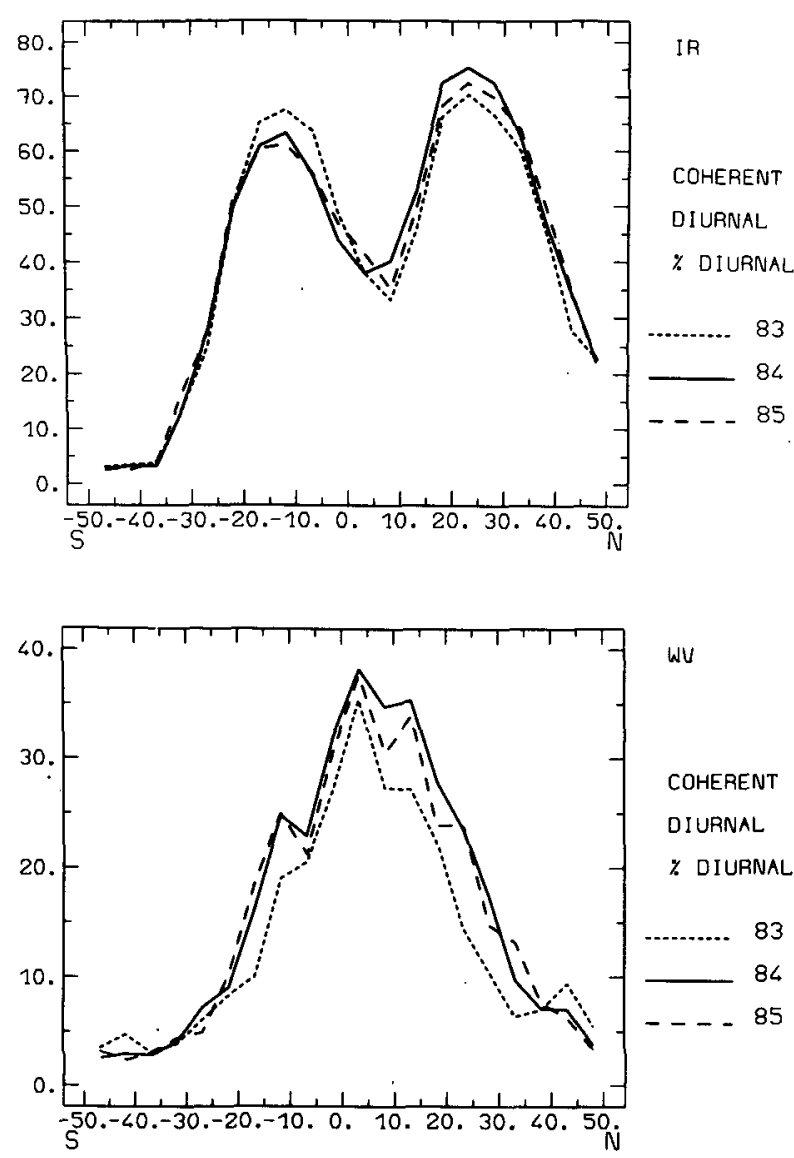

FIG. 7. Latitudinal distribution of the zonal average between $60^{\circ} \mathrm{E}$ and $60^{\circ} \mathrm{W}$ for the coherent diurnal variance as a percentage of the total intradiurnal variance.

tions is however very small compared to interdiurnal variations particularly over midlatitudes. The maximum intradiurnal variance is located over central Africa in relation to convective activity. The latitudinal distribution of these fluctuations gives maxima located in convective areas where there are passages of perturbations influencing cloud activity and the water vapor content of the midtroposphere at a diurnal scale.

Compared to the IR channel, the latitudinal distribution of the percentage of coherent diurnal variation (Fig. 7) in the WV channel shows a completely different shape with a single strong maximum between $0^{\circ}$ and $10^{\circ} \mathrm{N}$ and a decrease poleward to $30^{\circ} \mathrm{S}$ and $35^{\circ} \mathrm{N}$, reaching a value near zero at midlatitudes. This distribution shows that this coherent diurnal variation is not related only to convective activity, since it exists with a significant reproducible percentage $(15 \%-25 \%)$ over subsidence areas. In summer 1983 this quantity appears to be $10 \%$ lower than for the two other years. The spatial distribution of these variations (Fig. 6) presents two main maxima over central and East Africa and the general shape shows a large influence of the relief with, as for the atmospheric window, a lower coherent diurnal variation over lower terrain. A direct influence of the surface temperature diurnal variation over high land seems unlikely since the water vapor amount and cloud over these regions is large; in addition there is no high coherent diurnal fluctuation over high land of Madagascar where the mean amount of water vapor is lower. Another maximum is also present for the three summers over the South Atlantic upwelling at $15^{\circ} \mathrm{S}, 12^{\circ} \mathrm{E}$ and may be related to sea-breeze circulation. Over the Amazon basin, there is also a strong maximum (present in the IR window) related to high convective clouds mostly generated by seabreeze circulation (Kouski, 1980; Sun and Orlanski, 1981).

We present here only the amplitudes of those fluctuations which are related to diurnal variation in high cloud cover and in the water vapor content of the midtroposphere. The presence of this diurnal variation, especially in subsidence areas where no high cloud are present, is interesting since it detects a diurnal response of the midtroposphere to the solar forcing which may be associated with fluctuations of vertical motions or temperature. More detailed study on the origin and phase of these variations will be made in a forthcoming paper.

\section{c. Interdiurnal variations}

Spectral analysis of interdiurnal variations is interesting because dominant time scales of the fluctuations in the OLR signal can be pointed out. These time scales, associated with a given region for a given season, are an important climatic parameter as they are affected by the mean atmospheric state during the period studied. Long-term comparison of this type of analysis with results based on other sets of data will then give a better understanding of climatic anomalies. In addition, this point is a very important parameter for GCM validation because fluctuations are related to physical processes which may not appear by comparison of mean fields or by standard deviation fields without distinguishing time scales. With the use of satellite products, this information can be obtained even in regions sparsely or not at all covered by meteorological stations. Note that these interdiurnal fluctuations in the IR window are related not only to cloud activity but also to parameters such as the atmospheric extinction (water vapor, aerosols) or the surface temperature which also are a function of tropospheric conditions.

The aim of this section is not to point out periodic features detected by the way of the radiation fields but to study the dominant time scales of fluctuation in these fields as a function of the geographical location. From this point of view, the selection of the five spectral bands is not made using the location of apparent peaks in the spectra but rather by dividing the mean spectrum over the whole area and the three summers into spectral bands representing the same amount of variance. This 

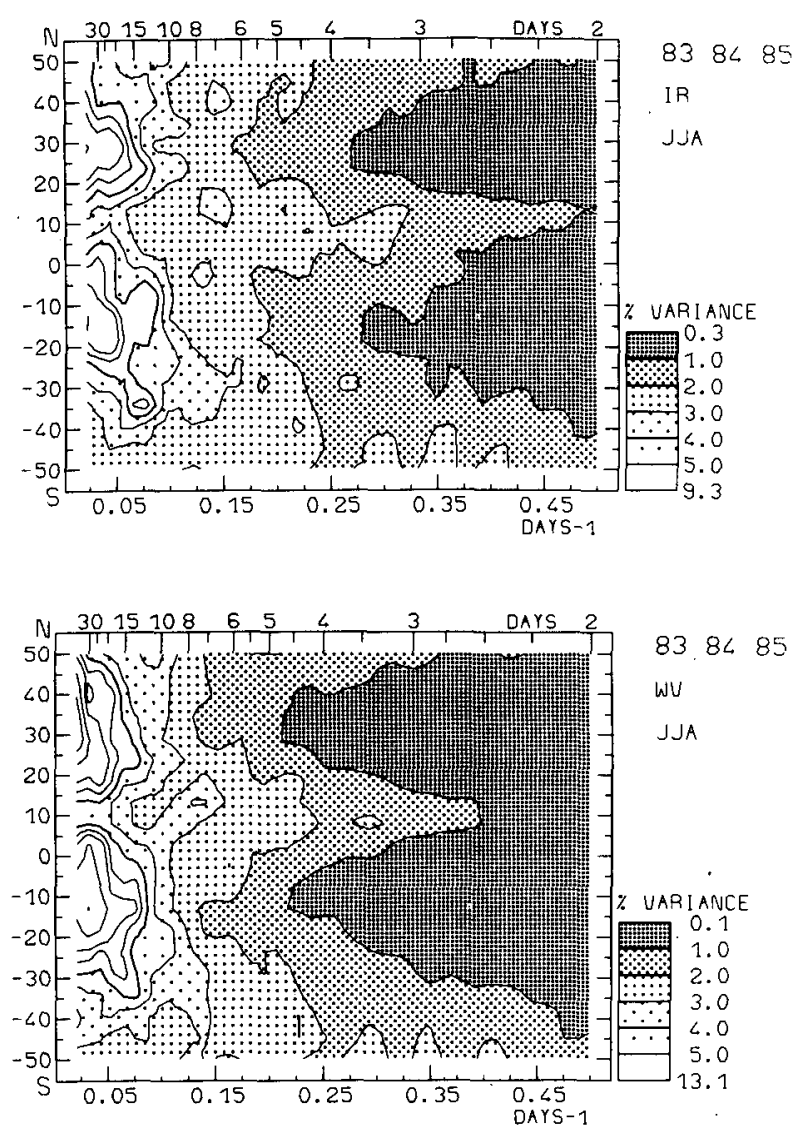

FIG. 8. Latitudinal distribution of the mean power spectra between $60^{\circ} \mathrm{E}$ and $60^{\circ} \mathrm{W}$ expressed as a percentage of the mean latitudinal variance for period longer than 2 days. White areas are divided into 5 isopercentage curves.

is obviously an arbitrary choice but it gives a coherent geographical distribution of time scales of fluctuation.

\section{1) LATITUDINAL DISTRIBUTION OF THE POWER SPECTRA}

Since the total interdiurnal variance presents large differences from one latitude zone to another, it is more interesting to look at the power spectra as a percentage of the mean zonal variance for periods longer than 2 days. This gives, in addition, a better basis of comparison between the two channels since the two latitudinal distributions of the interdiurnal variance were rather different (see Fig. 2).

Figure 8 shows large differences in the characteristic time scales of the interdiurnal fluctuations of the detrended signal from one latitude to the other. It is interesting to note the similarity between the percentage of variance density of the IR and the WV channels. This means that the time scales of the fluctuation are generally conserved despite the different quantities measured even in the subsidence zone where the correspondence between the two channels is not due to high cloudiness. The percentage of variance density of the WV signal is, however, more concentrated at low frequencies.

Both channels present large latitudinal differences in the time scales of fluctuations with concentration of the energy at low frequency in the subsidence regions and a large extension at periods of a few days for lowlevel convergence regions of midlatitudes or ITCZ. Around $30^{\circ} \mathrm{N}$, fluctuations at periods longer than 30 days represent $43 \%$ of the variance (of the detrended signal) in the WV channel and $31 \%$ in the IR. By contrast, around $40^{\circ} \mathrm{S}$ or $10^{\circ} \mathrm{N}$, this variance is lower than $10 \%$ in the two channels. If we look at fluctuations at time scales of a few ( 2 to 8 ) days, the percentage of variance is larger in convergence areas. At $7.5^{\circ} \mathrm{N}$ or for the southern midlatitudes, these fluctuations explain nearly $60 \%$ of the variance in the IR channel $(56 \%$ in the WV channel) whereas they represent only $30 \%$ at $30^{\circ} \mathrm{N}(21 \%$ in the WV). This shows the extreme range in the zonal mean characteristic time scales of the fluctuations related to the Hadley circulation.

Despite the zonal mean, Fig. 8 presents in addition a concentrated energy in the 3-4 and 4-5 day bands around $10^{\circ} \mathrm{N}$. This is undoubtedly related to easterly waves which cross West Africa and the Atlantic ocean during summer with periods in these frequency range. These waves may be detected in the radiation field by the way of cloud cover. (See, for example, Payne and McGarry, 1977.)

\section{2) REGIONAL DISTRIBUTION OF SPECTRAL VARI- ANCE}

For the study of variance at periods of a few days, we make initially a selection of five spectral bands chosen to represent $20 \%$ of the IR variance in the interdiurnal frequency domain and considering the mean spectrum over the 480 regions and the three summers. These bands were found to be as follows: band 1 from 1 day to 2.5 days; band 2 from 2.6 days to 4.6 days; band 3 from 4.8 days to 8.4 days; band 4 from 9.2 days to 18.4 days and band 5 longer than 23 days. The distribution of the bands along the mean IR spectrum shows the "red noise" character of this spectrum with a concentration of the energy at low frequency: The aim of this section is however to show substantial regional differences in the frequency distribution of the energy. Bands 2 and 3-hereinafter referenced as band B-are presented together since band 3 presents no significant maximum except over Atlantic Ocean around $10^{\circ} \mathrm{N}(30 \%)$. Since the last two bands contain only six and four harmonics, we consider only a bandhereinafter referenced as band $\mathrm{C}$-representing periods longer than 9.2 days. For each region, the variance in each band is presented (Figs. 9-11) as a percentage of the regional interdiurnal variance. As for the latitudinal distribution, this gives a better way of comparison between the two channels. In addition, this makes it pos- 

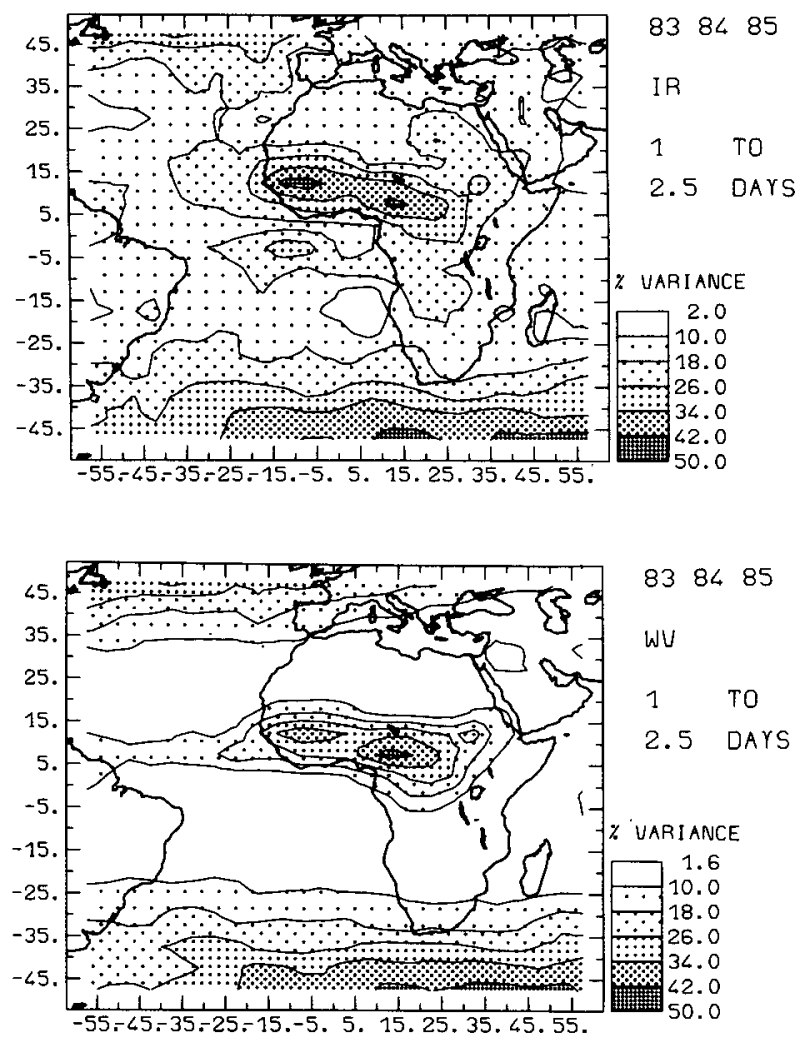

FIG. 9. Variance in the 1-2.5 day band as a percentage of the total interdiurnal variance of the detrended signal (mean over the three summers) (band A).

sible to study time scales even in regions where the total interdiurnal variance is weak.

Over the ITCZ, short time scales dominate ( 1 to 8.4 days) for the two channels related to the high convective cloud activity. An interesting shift is observed between the oceanic part, having a maximum percentage (up to $50 \%$ ) of variance explained in band $B$, and West Africa which appears to have two regions-located around $10^{\circ} \mathrm{N}$ at $15^{\circ} \mathrm{E}$ and $5^{\circ} \mathrm{W}$-strongly influenced by shorter time scales which represents more than $40 \%$ of the interdiurnal variance in band A (identical to band 1). Note that the IR interdiurnal variance is large over these regions (Fig. 2). These results over the land part of the ITCZ are in good agreement with results of Orlanski and Polinski (1977) who studied cloud cover over Africa for the March-May season using NOAA4 polar orbiting satellite. These authors, despite the different season studied, find also more variance in shorter time scales ( 1 to 3.25 days) than longer ones (3.25 to 10 days). Over central Africa, band B dominates (between 40 and $50 \%$ ) over cloudy regions and time scales become longer over and eastward of the East African Jet, attaining significant percentage (up to $45 \%$ ) in band $C$. For band $B$, there is a large region of maximum over the Atlantic Ocean for the IR window which is more concentrated around $10^{\circ} \mathrm{N}$ in the
WV channel. In the IR window, there is another maximum in band $\mathrm{A}$ ( $30 \%$ of the variance) centered at $\left(0^{\circ} \mathrm{N}, 10^{\circ} \mathrm{W}\right)$ with a zonal extent to the African coast. This maximum-which does not appear in the WV channel-is more related to low-level cloudiness and corresponds to the location of the equatorward limit of strong coherent diurnal variation of stratiform cloud (Fig. 6). This may be related to short-time-scale fluctuations of the northern limit of the stratiform cloud coverage. This may be also the case around $20^{\circ} \mathrm{N}$ where there is more percentage of variance in the IR than in the WV channel, corresponding also to fluctuation of the equatorward extent of the stratocumulus.

Over midlatitude regions bands $\mathrm{A}$ and $\mathrm{B}$ dominate as well with again a very good coherence between the two channels. For the southern regions, band B dominates southeast of the Brazilian coast and eastward around $35^{\circ} \mathrm{S}$ whereas band $\mathrm{A}$ has significant maxima (up to $40 \%$ ) east of $15^{\circ} \mathrm{E}$ and south of $40^{\circ} \mathrm{S}$. This shift is certainly related to the greater influence of band $B$ on the latitudinal extension of the midlatitude perturbations north of $35^{\circ} \mathrm{S}$ whereas times scales of regions further south are more related to cloud fluctuations in the perturbations themselves.

In subsidence regions, band $\mathrm{C}$ dominates clearly in both the channels. Over the Atlantic Ocean, there are two main maxima centered at $\left(25^{\circ} \mathrm{N}, 45^{\circ} \mathrm{W}\right)$ and
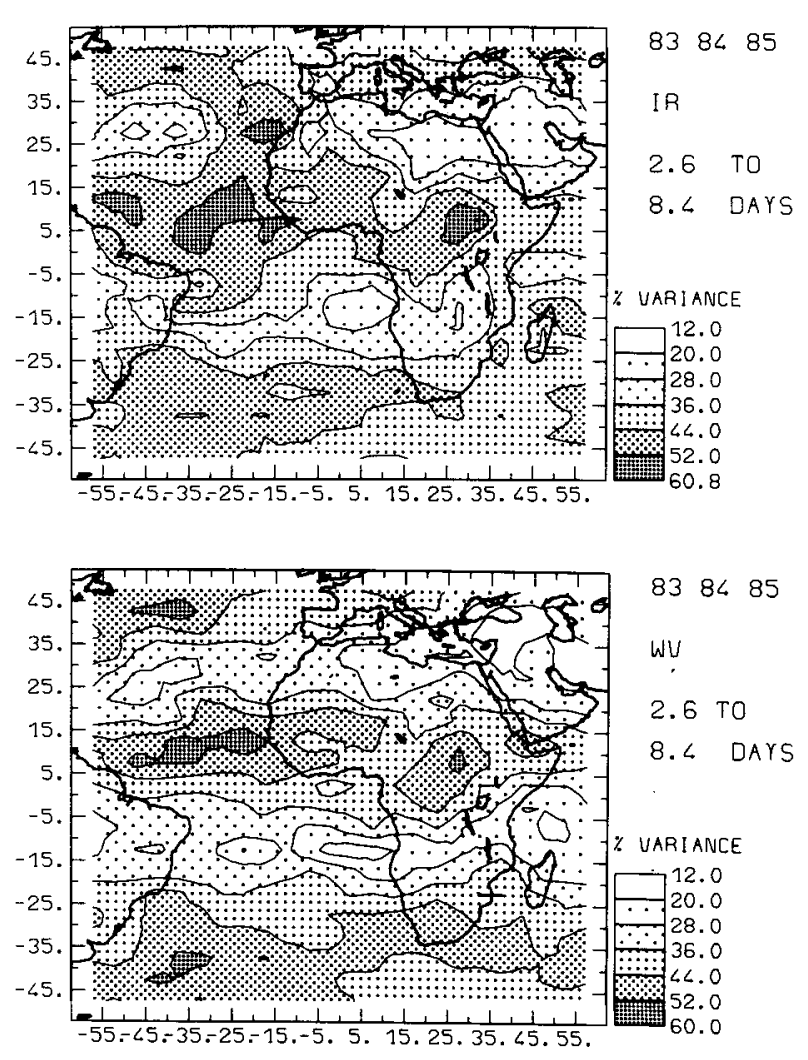

FIG. 10. As in Fig. 9 for the 2.6-8.4 day band (band B). 

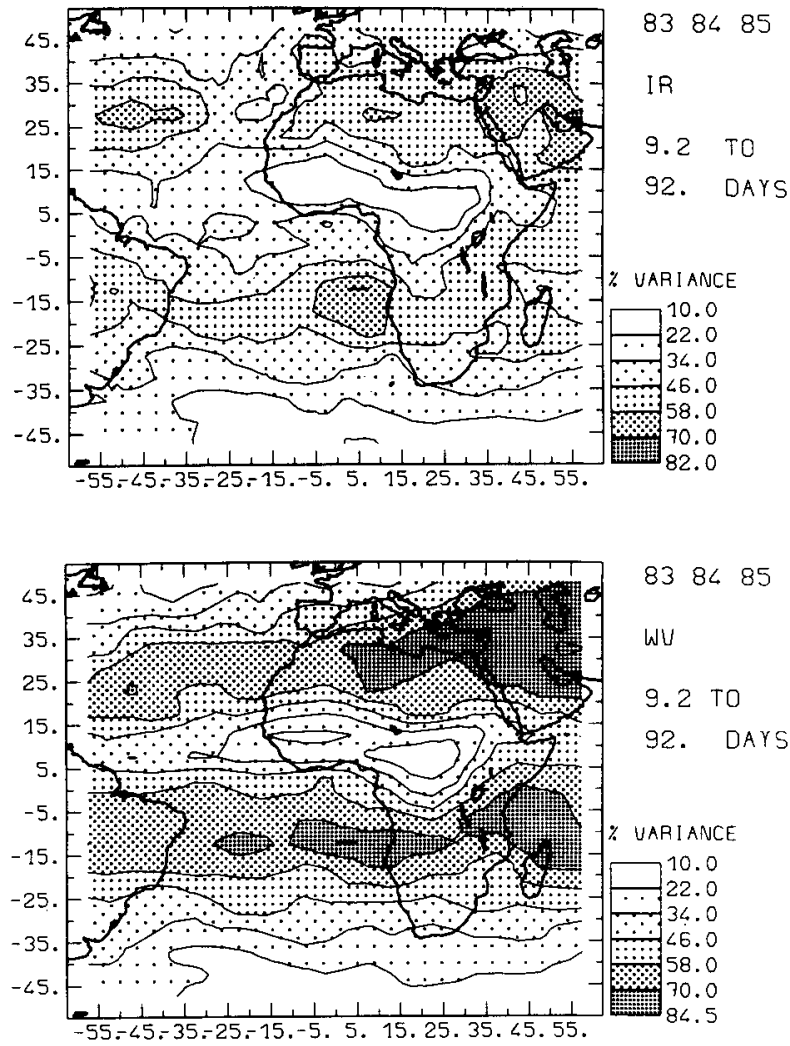

FIG. 11. As in Fig. 9 for periods longer than 9.2 days (band C).

$\left(15^{\circ} \mathrm{S}, 5^{\circ} \mathrm{E}\right)$ corresponding to location of low stratiform cloudiness. The very good coherence between the two channels seems to show a relation between the characteristic time scales of fluctuations of stratiform cloud and of fluctuations of the temperature and the water vapor amount of the midtroposphere. For the WV channel, there is another very strong maximum located around $35^{\circ} \mathrm{N}$ and extending eastward from $5^{\circ} \mathrm{E}$. In these regions, the percentage of variance in band 3 reaches values greater than $70 \%$ showing the very strong influence of long-time-scale fluctuations. This maximum also exists with less magnitude for the IR window which may be related both to the seasonal variation of surface temperature and atmospheric extinction. For the WV channel, around $45^{\circ} \mathrm{E}-10^{\circ} \mathrm{S}$, there is a strong maximum (up to $70 \%$ ) of the variance in band 3 which does not appear in the IR channel.

As for Atlantic Ocean regions around $20^{\circ} \mathrm{E}-30^{\circ} \mathrm{N}$ and $25^{\circ} \mathrm{E}-5^{\circ} \mathrm{S}$, this decoupling between the two channels shows that fluctuations in band $\mathrm{C}$ over these regions have a relatively small influence on the IR signal, compared to fluctuations in bands A and B. Note that this stronger decoupling occurs in subtropical regions at the east-west limits of the regions of higher pressure. On the contrary, at the centers of the high pressure regions there is a good correspondence between the time scales detected by the two channels.

\section{Discussion}

Three summers of data from the meteorological geostationary satellite METEOSAT have been examined in order to extract information on the fluctuations of infrared radiances (atmospheric window and water vapor band at 6-7 $\mu \mathrm{m}$ ) at interannual, intraseasonal and intradiurnal time scales.

Year-to-year differences of the seasonal mean fields (and of the seasonal standard deviations) reveal large regions of positive and negative values showing the large spatial coherence of interannual variability for boreal summer. On the basis of the $3 \mathrm{yr}$ studied, these differences in the IR mean field's reveal two large regions of high interannual sensitivity around NEB (northeastern Brazil) and SWA (southern West Africa). In addition, the mean WV field of summer 1983 reveals a weaker signal over the Northern Hemisphere up to $15^{\circ} \mathrm{N}$ and a stronger one between $15^{\circ} \mathrm{N}$ and $20^{\circ} \mathrm{S}$, suggesting a shift of the subsidence motion to the Southern Hemisphere.

The general trend of the interannual anomalies in the mean fields shows a local compensation around the area of anomaly. This may be partly explained by a displacement of a convergence area. Year-to-year differences between mean fields show, however, a structure where a positive (negative) anomaly is associated with two negative (positive) anomalies located north and south of the first one. This is the case over NEB where the jet has northward displacement between 1983 and 1985 explaining the two anomalies of opposite sign over NEB and regions further south. These anomalies are however related to the activity and the position of the Atlantic portion of the ITCZ located north of the NEB. This interannual fluctuation of the cloud activity over NEB may be associated with a westward extension of the subsidence area in 1983 explaining the southward shift in the position of the jet.

The effect of a translation of a convergence zone may also be seen in SWA, comparing 1984 and the two other years. The northern anomaly corresponds to a latitudinal displacement of the ITCZ over SWA. The southern anomaly is, however, related to the amount of stratiform cloud. Since this weak amount of cloud over the South Atlantic in 1984 coexists with the weak strength of the trades, this anomaly may also be related to the large-scale circulation.

Since these anomalies have a large zonal extent and also have a local compensation in the northern and southern directions, they suggest an interannual change mainly in the latitudinal large-scale circulation. However, in 1983 this latitudinal distribution of the anomaly is also a function of longitude around the $15^{\circ} \mathrm{W}$ axis, suggesting perturbations in the meridional circulation. This study of the IR radiation field is obviously not sufficient for a good understanding of the interannual fluctuation in the tropospheric circulation since we use nondynamical parameters on a restricted 
part of the earth. However, such a study reveals the response of very important parameters, such as the cloud cover or water vapor content of the midtroposphere, to interannual fluctuation of large-scale circulation. Further study is planned to relate these results to the global analysis from ECMWF.

The study of intradiurnal fluctuations reveals principally the diurnal variation of surface temperature in the IR window and intradiurnal fluctuation of high convective cloud in the WV band. Looking at the coherent diurnal variation, oceanic regions appear to have a strong diurnal response to solar forcing due to stratiform cloud. Over the land part of the ITCZ, while northern regions have strong coherent diurnal variation mainly due to thunderstorm development, regions further south have a weaker response to the solar forcing. Over the oceanic part of the ITCZ, this response is very weak. In the IR window, the major part of the regions having a strong coherent diurnal variation are located in the subsidence area and are dominated by the surface temperature or the low-level cloudiness. On the contrary, in the WV band, the regions with strong coherent diurnal variation are located in the tropical band in relation to deep convection and with stronger magnitude over highlands. There is however a significant percentage of coherent diurnal variation over subsidence areas.

The proportion of coherent and "incoherent" diurnal variation is an important parameter since it reveals the magnitude of the response of the regions to the solar forcing relative to intradiurnal fluctuations forced by larger-scale perturbations. In addition, this parameter makes it possible to evaluate the error due to the use of the coherent diurnal variation to interpolate results from polar-orbiting satellites (two measures per day). While, by definition, the "incoherent" diurnal variation is zero, on average, over the 3 months, these fluctuations, generated by cloud development at a random hour of the day, may have a strong influence on estimates of parameters, such as the radiation budget components, strongly coupled with the solar cycle.

The study of interdiurnal fluctuations reveals very good coherence between the regional time scales in the two channels despite the different quantities measured. Results show a progressive shift of the location of maximum spectral variance from the short time scales in convergence areas to long time scales in subsidence regions. Despite the nearly zonal configuration, there is also a longitude-dependent distribution with time scales decreasing westward from the Atlantic ocean at $15^{\circ} \mathrm{N}$ to SWA and from the southern coast of Brazil to regions southward of South Africa.

The good coherence between the two channels tends to show that the same time scales dominate over a vertical extent from the lower to the midtroposphere for most of the regions studied and then may be related to fluctuations of dynamical tropospheric parameters.
However, while such a relation has been confirmed in convective regions (Nitta, 1984), its existence over other regions needs further investigation.

Acknowledgments. This research was supported in part by the Centre National d'Etudes Spatiales, and it was carried out in part at the Service d'Aéronomie du CNRS (Verrières-le-Buisson) as well as at LMD/Palaiseau. I would like to thank R. S. Kandel, D. Cadet and $M$. Desbois for stimulating discussions and useful comments.

\section{REFERENCES}

Duvel, J. P., and R. S. Kandel, 1985: Regional-scale diurnal variations of outgoing infrared radiation observed by METEOSAT. J. Climate Appl. Meteor., 24, 335-349.

Hartmann, D. L., V. Ramanathan, A. Berroir and G. E. Hunt, 1986: Earth radiation budget data and climate research. Rev. Geophys., 24, 439-468.

- , and E. E. Recker, 1986: Diurnal variation of outgoing longwave radiation in the tropics. J. Climate Appl. Meteor., 25, 800-812.

Horel, J. D., V. E. Kouski and M. T. Kagano, 1986: Atmospheric conditions in the Atlantic sector during 1983 and 1984. Nature, 322, 248-251.

Jones, M., and J. Morgan, 1981: Adjustment of METEOSAT-1 radiometer response by ground processing. ESA J., 5, 305-320.

Julian, P. R., 1971: Some aspects of variance spectra of synoptic scale tropospheric wind components in midlatitudes and in the tropics. Mon. Wea. Rev., 99, 954-965.

Katz, E. J., P. Hisard, J. M. Verstraete and S. Garzoli, 1986: Annual change of sea surface slope along the equator of the Atlantic Ocean in 1983 and 1984. Nature, 322, 245-247.

Kouski, V. E., 1980: Diurnal rainfall variation in Northeast Brazil. Mon. Wea. Rev., 108, 488-498.

Kraus, G. B., and L. D. Leslie, 1982: The interactive evolution of the oceanic and atmospheric boundary layers in the sources regions of the trades. J. Atmos. Sci., 39, 2760-2772.

Lamb, P. J., R. A. Peppler and S. Hastenrath, 1986: Interannual variability in the tropical Atlantic. Nature, 322, 238-243.

Lau, R. M., and P. H. Chan, 1985: Aspects of the 40-50 day oscillation during the Northern winter as inferred from outgoing longwave radiation. Mon. Wea. Rev., 113, 1889-1909.

Martin, F. L., and V. V. Salomonson, 1970: Statistical characteristics of subtropical jet stream features in terms of MRIR observations from Nimbus 2. J. Appl. Met., 9, 508-520.

Minnis, P., and G. F. Harrison, 1984: Diurnal variability of regional cloud and clear sky radiative parameters derived from GOES data, II, November 1978 cloud distributions. J. Climate Appl. Meteor., 23, 1012-1031.

Murakami, T., L. X. Chen and A. Xie, 1986: Relationship among seasonal cycles, low-frequency oscillations, and transient disturbances as revealed from outgoing longwave radiation data. Mon. Wea. Rev., 114, 1456-1465.

Nieuwolt, S., 1977: Tropical Climatology. Chichester, Wiley \& Sons, $207 \mathrm{pp}$.

Nitta, T., Y. Nakagoni, Y. Suzuki, N. Hasegawa and A. Kadokura, 1984: Global analysis of the lower tropospheric disturbances in the tropics during the Northern Summer of FGGE year. Part I: Global features of the disturbances. J. Met. Soc. Japan., 63, 118.

Orlanski, I., and L. J. Polinski, 1977: Spectral distribution of cloud cover over Africa. J. Met. Soc. Japan., 55, 483-493.

Paegle, J., and J. E. Geisler, 1986: The effect of east african topography on flow driven by zonally symmetric forcing. J. Atmos. Sci., $\mathbf{4 3}$, 1862-1872. 
Payne, S. W. and M. M. McGarry, 1977: The relationship of satellite inferred convective activity to Easterly waves over West Africa and the adjacent Atlantic Ocean during phase III of GATE. Mon. Wea. Rev., 105, 413-420.

Philander, S. G. H., 1986: Unusual conditions in the tropical Atlantic Ocean in 1984. Nature, 322, 236-238.

Ramond, D., M. Corbin, M. Desbois, G. Szejwach and P. Waldteufel, 1981: The dynamics of polar jet streams as depicted by the METEOSAT Water Vapor channel radiance field. Mon. Wea. Rev., 109, 2164-2175.

Schiffer, R. A., and W. B. Rossow, 1983: The International Satellite Cloud Climatology Project (ISCCP): The first project of the World Climate Research Programme. Bull. Am. Meteorol. Soc., 64, 779-784.

Short, D. A., and J. M. Wallace, 1980: Satellite-inferred morning- to-evening cloudiness changes. Mon. Wea. Rev., 108, 1160-1169.

Stewart, M. R., and H. E. Fuelberg, 1986: Relationship between 6.7 micrometers imagery and radiosonde-derived parameters, Second Conference on Satellite Meteorology/Remote Sensing and applications. A.M.S., Williamsburg, Va, May 13-16, 1986.

Sun, N. Y., and I. Orlanski, 1981: Large mesoscale convection and sea breeze circulation, Part I: Linear stability analysis. J. Atmos. Sci., 38, 1675-1693.

Weickmann, K. M., 1983: Intraseasonal circulation and outgoing longwave radiation modes during northern hemisphere winter. Mon. Wea. Rev., 111, 1838-1858.

Weisberg, R. H., and C. Colin, 1986: Equatorial Atlantic ocean temperature and current variations during 1983 and 1984. Nature, 322, 240-245. 